\title{
Use of gamma irradiation for decorative coloring of glass in the Moroccan NIAR facility
}

\author{
Youssef El-ouardi 1,*, Adil Aknouch ${ }^{2}$, Ahmed Dadouch ${ }^{1}$, Mohammed Mouhib ${ }^{3}$, and Mounir Benmessaoud ${ }^{1}$ \\ ${ }^{1}$ Nuclear Engineering Group, LIMAS Laboratory, Department of Physics, Faculty of Science Dhar El Mahraz,University Sidi \\ Mohamed Ben Abdellah, City Fez,Morocco. \\ ${ }^{2}$ Department of Physics, Nuclear Physics and Techniques Team, Faculty of Science, Ibn Tofail University, Kenitra, Morocco \\ ${ }^{3}$ National Institute for Agronomical Research (NIAR), Irradiation Facility of Boukhalef (SIBO), Tangier, Morocco.
}

\begin{abstract}
The applications that cover the use of ionizing radiation are numerous, very diverse and belong to several fields of activity such as, the medical and agricultural fields etc. The aim of this work is to highlight an application of decorative glass coloring by gamma radiation. Crystal white glass cups are placed on small rotating tables and subjected to exposure to gamma radiation from the cobalt-60 gamma irradiator of the National Institute of Agronomic Research (INRA-Morocco / Tangier) for doses between 0 and $1.5 \mathrm{KGy}$. The results obtained show the variation in the color of glass between light brown to dark brown depending on the absorbed dose.

Keywords: Decorative coloring, Crystal white glass, gamma radiation, cobalt-60, absorbed dose.
\end{abstract}




\section{Introduction}

The uses of ionizing radiation in human life cover several fields, such as industry, medicine, agriculture and in scientific research etc.[1] They therefore have several benefits for humans. Morocco is among the most usable African countries for ionizing radiation in several activities, for example in medicine, ionizing radiation ( $\mathrm{x}$ and gamma) is used in radiology and in radiotherapy to diagnose and treat cancer(gammaknife technique for example), also in nuclear medicine radioactive elements are injected into the human body (radiopharmaceuticals) for treatment and diagnosis (thyroid cancer with radioactive iod-123).[2-6] In addition to medicine, ionizing radiation is used in the industrial field in several applications such as electron beam welding or Checking the homogeneity of a metal generally using Iridium 192 (gamma radiography). The applications of ionizing radiation extend to a very important and sensitive area for the Moroccan economy which is agriculture, for this a gamma irradiator has been installed since 1995 at the National Institute of Agronomic Research (NIAR) in the city of Tangier, is considered unique in Morocco, since its installation there was several researches in this field, for the preservation of food, inhibition of germination, production of new varieties etc, indeed several products have been irradiated like sensitive oils, dried figs, strawberries, oranges, and all with the aim of progressing and developing Moroccan agriculture and increasing production yield.[2-5] In this work, we will be promoting a very important application of gamma radiation other than those in the agricultural sector, it is the decorative coloring of glass by gamma radiation coming from the NIAR irradiator. In this term, small cups of crystal white glass were irradiated at different doses of between 0 and 1500Gy. The results show the variation in glass color between light brown to dark brown depending on the amount of the dose absorbed.

\section{Materials and methods}

\subsection{NIAR irradiator}

The NIAR irradiator currently comprises 8 source pencils of cobalt-60 distributed in a circular formation $14 \mathrm{~cm}$ in diameter forming the source cage of the irradiator, each pencil is double encapsulated in two layers of nickel and closed at its end by two tips (figure 1).[3] Cobalt-60 is a radioisotope with a period of 5.2714 years which causes the emission of two gamma rays of energy respectively 1.173 and $1.332 \mathrm{MeV}$ following each decay by transforming to stable nickel-60. Table 1 gives the activity of 8 source pencils according to the calibration date. $[2,5]$
Table 1. Individual activity of each pencil NIAR irradiator cobalt- 60 .

\begin{tabular}{|c|c|c|}
\hline Source Number & calibration date & Activity (Ci) \\
\hline 1 & $27-03-2000$ & 726.83 \\
\hline 2 & $27-03-2000$ & 726.83 \\
\hline 3 & $01-10-2013$ & 10500 \\
\hline 4 & $01-10-2013$ & 10900 \\
\hline 5 & $01-10-2013$ & 10600 \\
\hline 6 & $01-10-2013$ & 10700 \\
\hline 7 & $01-10-2013$ & 11000 \\
\hline 8 & $01-10-2013$ & 10400 \\
\hline
\end{tabular}
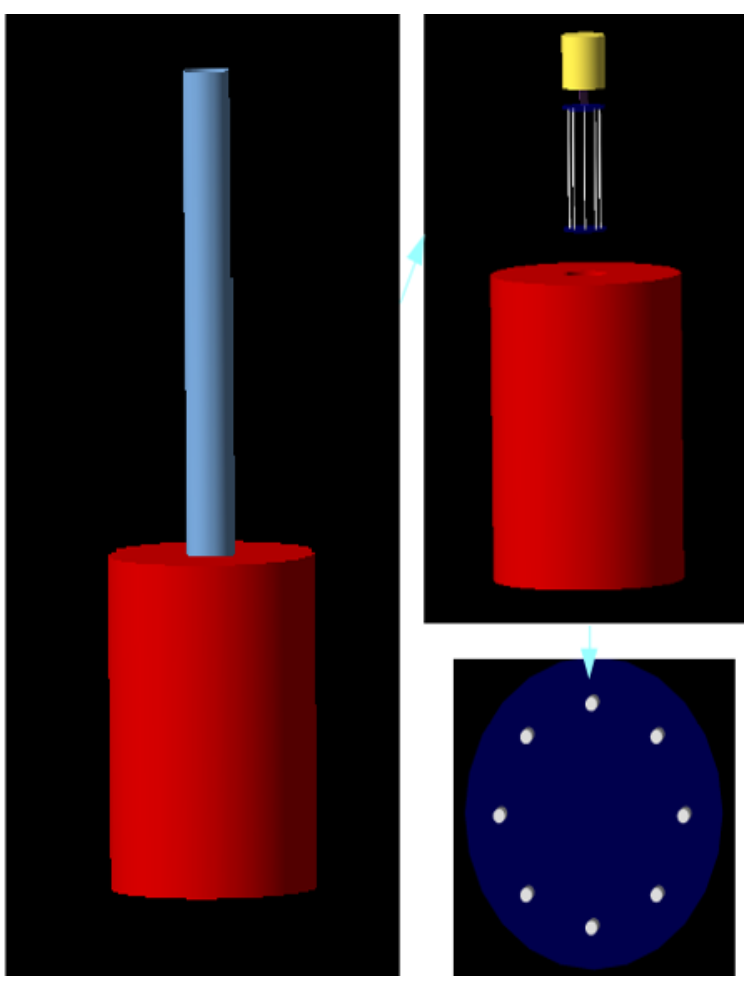

Fig. 1. The source cage and its storage container

As shown in figure 2, the NIAR ionization cell is of parallelepipedal shape $257 \mathrm{~cm}$ high, $605 \mathrm{~cm}$ along X, 570 $\mathrm{cm}$ along $\mathrm{Y}$, the gamma irradiator is surrounded by a set of rotating tables on which the products to be irradiated are posed, 9 tables have been installed to meet the irradiation needs in terms of quantity and irradiation time, in fact the $\mathrm{T} 1$ to $\mathrm{T} 6$ tables are used for irradiating large quantities at medium dose rate, the $\mathrm{T} 7$ tables and T8 are used for high and medium dose rate irradiation of agricultural or non-agricultural products such as pharmaceuticals or glass (subject of this work), the last turntable which is the T9 table is used for low doses.[1,3,4] 
(a)

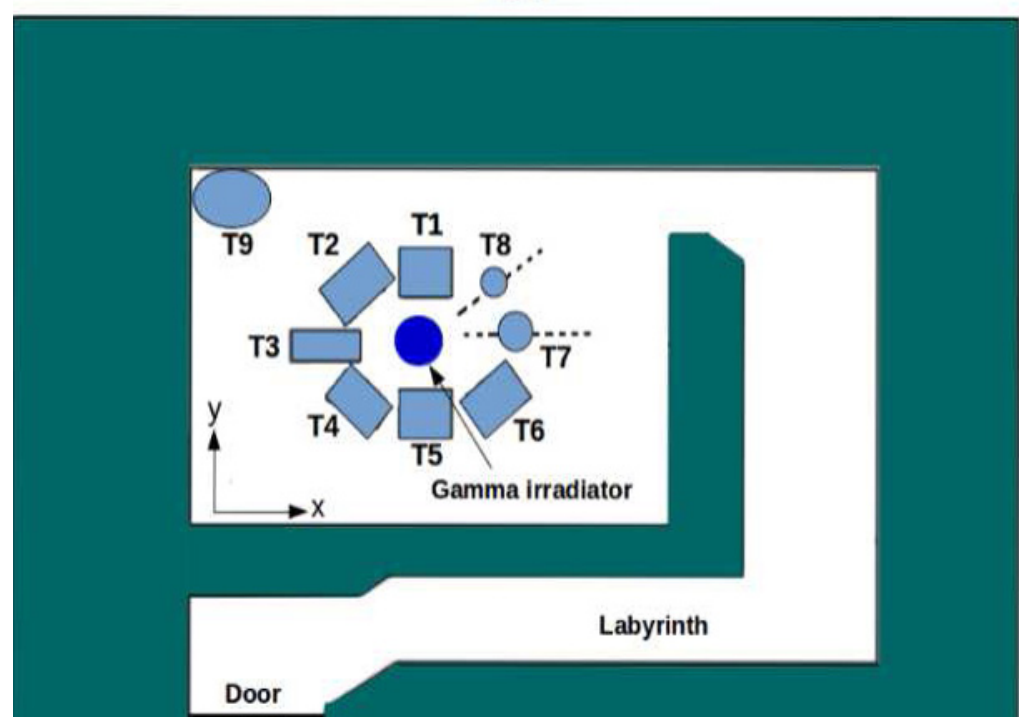

(b)

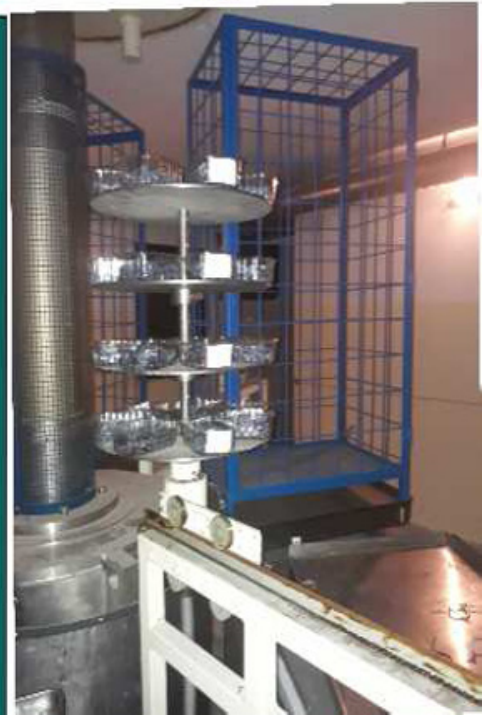

Fig. 2. (a) schematic view of the NIAR irradiation casemate, (b) actual view of the interior of the casemate during irradiation of an agricultural product.

In order to protect the NIAR population (especially the irradiator operators) and the environment, the source cage is stored during the hours of non-activity in a lead container, the walls of the casemate are made of reinforced concrete of $163 \mathrm{~cm}$ thick, the casemate door is armed, and the labyrinth is to eliminate radiation leakage through the door during irradiation.[1]

\subsection{Glass sample}

In this work we use new white crystal glass cups, 8 samples divided into 4 sets of which each set contains 2 units. One set will be used as a control (not irradiated), one for irradiated at $0.5 \mathrm{KGy}$, the third for irradiation at $1 \mathrm{KGy}$ and the fourth for irradiation at $1.5 \mathrm{KGy}$ (see figure 3).[7]

\section{Results and discussions}

The results obtained after irradiation of the samples are presented in figure 4, clearly showing the variation in color between light brown to dark brown as a function of the dose absorbed. The variation in color stops during saturation for a maximum dose (for doses greater than $1.5 \mathrm{KGy}$ ), this variation in color by irradiation effect is accompanied by variation in the optical properties of glass (optical density, index of refraction etc.) but the physical properties (such as hardness) remain the same which is an advantage for this coloring technique. In addition, the irradiated samples can be handled with complete safety, while there is no contamination by radiation.[8]

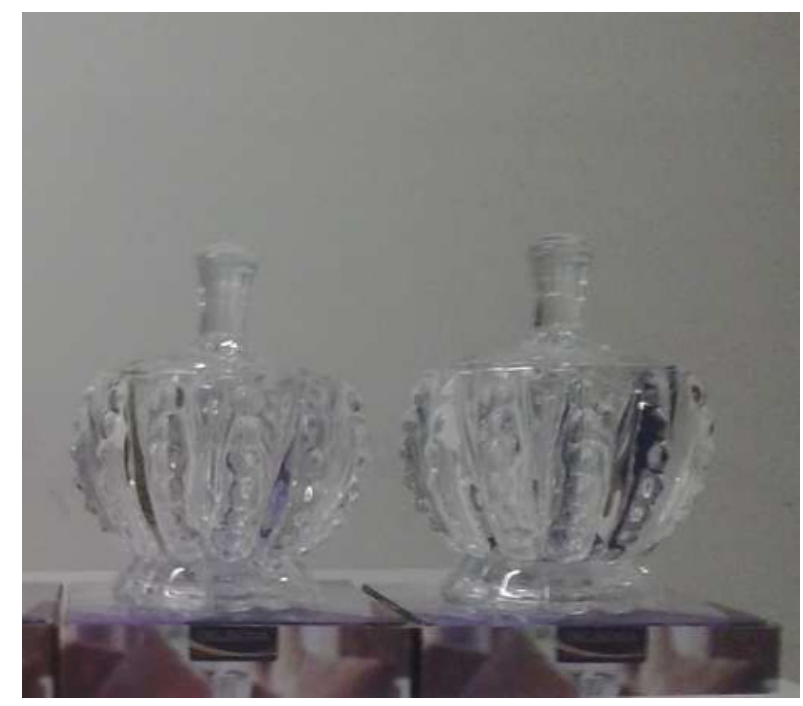

Fig. 3. Glass samples used in this study.

In addition, the colors obtained are stable, in fact they have little influence under normal temperature and pressure conditions and the discoloration (reverse effect) can only be done at high temperature (in an oven). [9,10]

There are many advantages to other ordinary glass coloring techniques, we can cite them as follows, firstly there is no waste that comes from the breakage of products, 


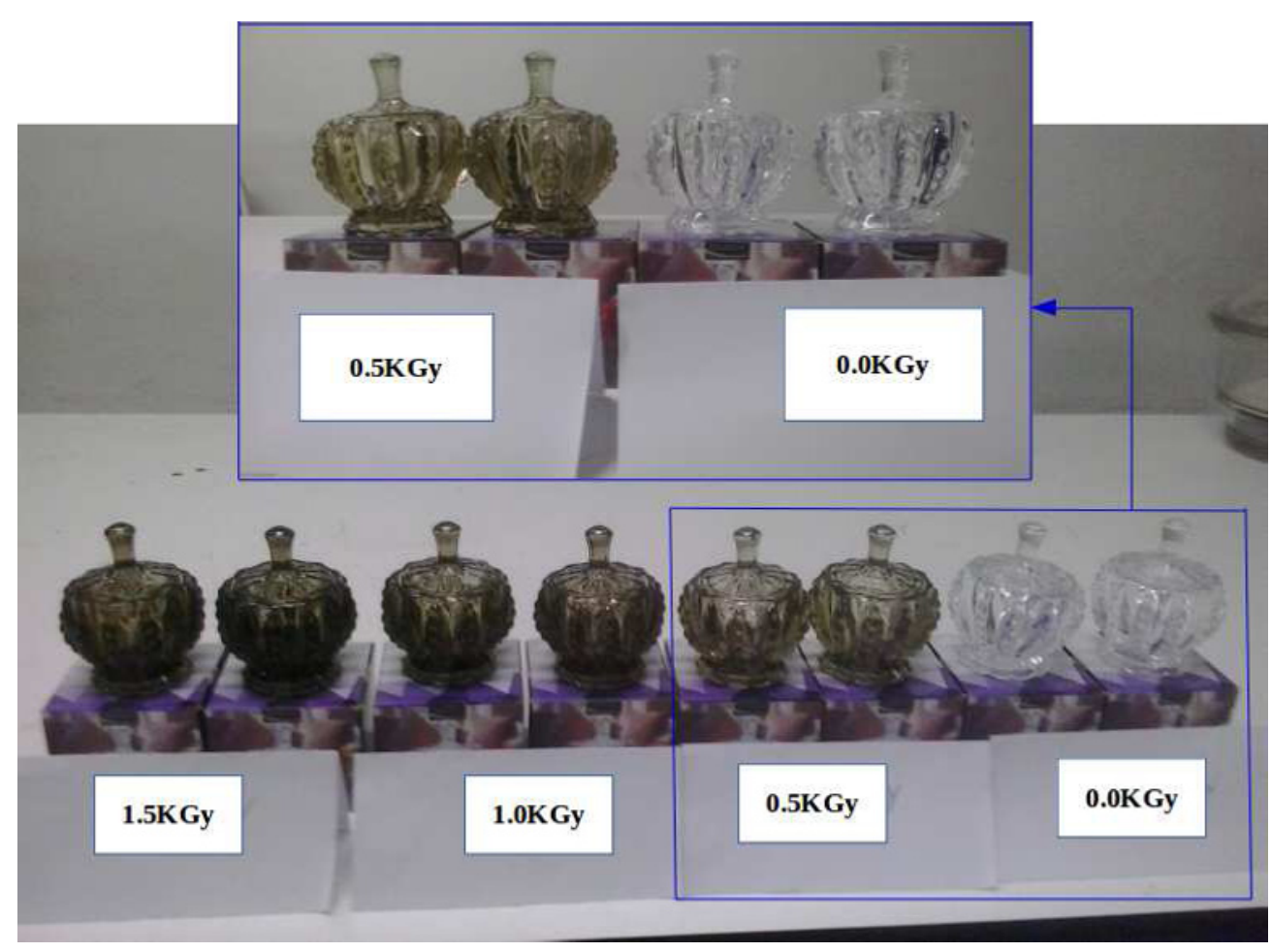

Fig. 4. Samples after irradiation for different absorbed doses.

secondly there is no addition of additives (products chemicals) which can contaminate the consumer over time (discoloration effect), the colors are special and difficult to obtain by ordinary coloring.

\section{Conclusion}

A promotion of the technique of decorative glass coloring in the NIAR facility was made in this study, it was shown the formation of special colors (dark yellow, dark brown) on crystal glass by irradiation effect. The colors obtained are stable and glassy products can be used with confidence afterwards. In addition, in this work the competence of NIAR irradiator has been shown to satisfy other requirements than those related to the field of agriculture. Other applications may take place in the future such as sterilization of blood and pharmaceuticals.

\section{References}

1. M. Mouhib, M. Chentouf, A. Guessous, NUKLEONIKA, 62, 303-309. (2017)

2. A. Aknouch, M. Mouhib, R. Sebihi, A. Didi, Y. Elouardi, A. Boubekraoui, A. Choukri, Moscow University Physics Bulletin, 75, 35-38. (2020)

3. Y. El-ouardi, A. Dadouch, A. Aknouch, M. Mouhib, A. Maghnouj, A. Didi, Moscow University Physics Bulletin, 75(5), 507-511(2020)

4. Mouhib Mohammed, Chentouf Mouad, Guessous Amina, Rostislav Vlaev, J. Chem. Chem. Eng., 11, 95101(2017)

5. A. Aknouch, Y. Elouardi, M. Mouhib, R. Sebihi, A. Didi, A. Choukri, Moscow University Physics Bulletin, 75 ,447- 450(2020)

6. O. Kadri, F. Gharbi, K. Farah, and A. Trabelsi, Int. J. Theor. Phys 14, 1 (2009)

7. H.A. Elbatal, Z. Mandouh, H. Zayed, S.Y. Marzouk, G. Elkomy, A. Hosny, Gamma ray interactions with undoped and $\mathrm{CuO}$-doped lithium disilicate glasses, Physica B 405 (2010) 4755-4762

8. A.S. El-Bayoumi, Huda A. Alazab, F.M. Ezz-ElDin, Journal of Non-Crystalline Solid 551(2021)120459 https://doi.org/10.1016/j.jnoncrysol.2020.120459

9. Miriam Chligui, Etude des propriétés optiques et mécaniques des verres binaires silicatés d'alcalins lourds, THÈSE, Université d'Orléans, 2010. Français.

10. Zhenlin Wang, Laifei Cheng, Materials Research Bulletin 92 (2017) 104-112 